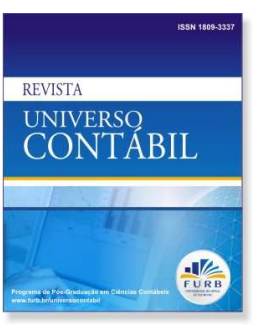

Revista Universo Contábil, ISSN 1809-3337

FURB, v. 5, n.4, p. 06-26, out./dez., 2009

doi:10.4270/ruc.2009428

Disponível em www.furb.br/universocontabil

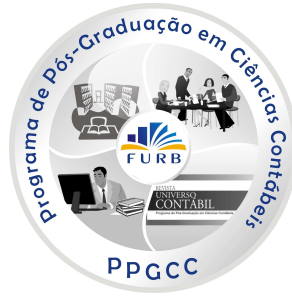

\title{
A RELAÇÃO ENTRE GERENCIAMENTO DE RESULTADOS CONTÁBEIS E O CUSTO DE CAPITAL DAS COMPANHIAS ABERTAS BRASILEIRAS*
}

\section{THE RELATIONSHIP BETWEEN ACCOUNTING EARNINGS MANAGEMENT AND BRAZILIAN PUBLIC COMPANIES' COST OF CAPITAL}

\author{
Paula Carolina Ciampaglia Nardi \\ Mestre em Controladoria e Contabilidade: FEA-RP/USP \\ Endereço: Rua Abrahão Issa Halack, 2145, Ribeirania \\ CEP: 14096-175 - Ribeirão Preto/SP - Brasil \\ E-mail: paula.nardi@yahoo.com.br \\ Telefone: (16) 3602-4746
}

Ricardo Luiz Menezes da Silva Mestrando em Controladoria e Contabilidade: FEA-RP/USP

Endereço: Rua Renato Rossi, 136, Marincek CEP: 14061-060 - Ribeirão Preto/SP - Brasil

E-mail: rlmsilva@terra.com.br

Telefone: (16) 3602-4746

Sílvio Hiroshi Nakao

Doutor em Controladoria e Contabilidade pela FEA/USP

Professor da FEA-RP/USP

Endereço: Av. Bandeirantes, 3900, Monte Alegre

CEP: 14040-900 - Ribeirão Preto/SP - Brasil

E-mail: shnakao@usp.br

Telefone: (16) 3602-4746

Maurício Ribeiro do Valle

Doutor em Controladoria e Contabilidade pela FEA/USP

Professor da FEA-RP/USP

Endereço: Av. Bandeirantes, 3900, Monte Alegre

CEP: 14040-900 - Ribeirão Preto/SP - Brasil

E-mail: marvalle@usp.br

Telefone: (16) 3602-4746

\footnotetext{
Artigo recebido em 06.10.2008. Revisado por pares em 09.12.2008. Reformulado em 09.03.2009. Recomendado em 18.03.2009 por Ilse Maria Beuren (Editora). Publicado em 30.11.2009. Organização responsável pelo periódico: FURB.
} 


\section{RESUMO}

O objetivo deste trabalho foi verificar a relação entre o gerenciamento de resultados contábeis e o custo de capital próprio e de terceiros das empresas brasileiras de capital aberto. Os dados foram obtidos do Economática ${ }^{\circledR}$ para o período de 2004 a 2006. Foram utilizados os modelos Jones Modificado, Teoh e KS para cálculo do accrual discricionário, proxy para gerenciamento de resultados, a qual representa a variável independente nesse estudo. As medidas representativas de custo de capital, ou variáveis dependentes, foram: beta (custo de capital próprio), Ki e Kd (custo de capital de terceiros). Para verificar a relação entre gerenciamento de resultados e o custo de captação das empresas foram feitas análises descritivas, de posição, correlação de Pearson e de Spearman e diferença de médias por meio do teste não-paramétrico Mann-Whitney. Como resultado, verificou-se uma relação positiva entre gerenciamento de resultados contábeis e custo da dívida, ou seja, quanto maior o nível de gerenciamento das empresas maior o custo de capital de terceiros. Mas não foi possível verificar qualquer relação entre o gerenciamento de resultados e o custo de capital próprio.

Palavras-chave: Gerenciamento de resultados. Accruals discricionários. Custo de capital.

\section{ABSTRACT}

The purpose of this study was to investigate the relationship between the accounting earnings management and the cost of capital of Brazilian companies. The data were obtained from Economática ${ }^{\circledR}$ in the period from 2004 to 2006. The models Modified Jones, Teoh and KS were used for calculating the discretionary accrual, proxy for earnings management, which represents the independent variable in this study. The representative measures of cost of capital, or dependent variables were: beta (cost of equity), Ki and $K d$ (cost of debt). To investigate the relationship between management performance and the borrowing cost for companies, descriptive statistics, Pearson and Spearman's correlation, and average differences were analyzed through the non-parametric Mann-Whitney test. As result, there was a positive relationship between earnings management and cost of debt. However, it was not possible to find any relations between earnings management and cost of equity.

Keywords: Earnings management. Discritionary accruals. Cost of capital.

\section{INTRODUÇÃO}

Sob a luz da teoria de agência, sabe-se que as pessoas procuram maximizar a própria utilidade, ou seja, buscam alcançar interesses particulares. Isso ocorre apesar da existência de contratos entre as partes com cláusulas restritivas a certas ações dos agentes que podem ser contrárias aos interesses do principal. O motivo é que tais contratos não conseguem abranger todas as possíveis atitudes oportunistas que um agente pode vir a ter em detrimento à riqueza do principal, consequência, dentre outros fatores, da não simetria de informações entre as partes. Sabendo disso, o principal tende a se sentir mais seguro quanto menor a assimetria informacional entre ele e a empresa, ou seja, quando recebe informações condizentes com a realidade econômico-financeira da companhia, quando essas informações são confiáveis e transparentes. Nesse contexto, o principal sente-se num ambiente de maior segurança e pode reduzir seu prêmio pelo risco do capital investido ou emprestado. Mas, caso contrário, ou seja, quando se tem poucas informações ou quando estas possam ser consideradas duvidosas, o 
principal se sente em um contexto de maior ameaça e em posição arriscada, o que o induz a elevar seu prêmio pelo risco, o qual é conhecido como prêmio pelo risco da falta de informação.

A falta de informação pode gerar custos, os quais, juntamente com outros, compõem os custos de agência. Segundo Jensen e Smith (1985, p. 3), tais custos incluem: custos de contratação, custos de transação, custo de risco moral e custos de informação. Para entender o problema de agência deve-se reconhecer que as partes de um contrato carregam custos de agência e procuram maximizar seus próprios interesses. Nesse sentido, de acordo com Andrade e Rossetti (2004, p. 324), a existência de contratos incompletos, assimetria de informação e risco moral abre espaço para a divergência de interesses entre acionistas e administradores, ocasionando custos atribuídos ao oportunismo destes.

Mas, à contabilidade como sistema de informação capaz de identificar, mensurar e reportar a realidade do desempenho econômico e financeiro da empresa, compete fornecer informações aos usuários de modo a auxiliá-los no processo de tomada de decisão, dando a eles bases consistentes para análise da companhia e subsequente tomada de decisão quanto à alocação de seus recursos. Complementarmente, Paulo (2007, p. 10) destaca que a contabilidade tem o papel de reduzir a assimetria informacional, minimizando os conflitos de interesses e contribuindo para uma alocação de recursos mais adequada no mercado de capitais. Porém, as normas contábeis permitem que os gestores tenham certa discricionariedade ao optarem por tipos de práticas e escolhas de critérios contábeis.

Nesse ponto, pesquisas internacionais e nacionais verificaram que certas escolhas são feitas com o intuito de alterar a imagem do real desempenho econômico-financeiro da companhia, a ponto de iludir os usuários quanto à performance da companhia, fato ligado ao Gerenciamento de Resultados (GR). Nesse caso, o objetivo de reduzir a assimetria de informações e contribuir para alocação de recursos mais segura, por parte dos financiadores, pode não ser alcançado conforme se esperava. Assim, diz-se que o GR, nesse sentido, pode ser uma maneira de o gestor, oportunistamente, maximizar sua riqueza em detrimento do patrimônio dos acionistas e dos credores. Contudo, vale ressaltar que o GR é uma maneira que pode ser utilizada para manipular as informações contábeis frente outras, como: gerenciamento por decisões operacionais; manipulação por classificação nas demonstrações contábeis, em que o gestor pode usar possibilidades de classificação das contas e interferir na análise de indicadores; e mesmo manipulações fraudulentas.

De tal modo, quando se escolhe o que, como ou quando divulgar uma informação, o administrador causa impacto no resultado da empresa, podendo influenciar, por sua vez, a qualidade e a transparência dessa informação. Consequentemente, ocorre assimetria de informações e caracteriza-se um problema de agência. Nesse contexto, Martinez (2001, p. 4) afirma que a informação contábil pode afetar a distribuição de riqueza do investidor, a percepção do risco, as taxas de investimento e a forma como os recursos são alocados entre empresas. Assim, uma informação que não reflete a real situação econômica da empresa pode comprometer a análise e decisões de alocação de recursos de investidores e credores.

Nessa linha, pesquisas internacionais verificaram se a qualidade dos resultados divulgados pelas empresas interfere em seus custos de captação. A título de exemplo pode-se citar os estudos de Francis et al. (2002, p. 2), Francis, Khurana e Pereira (2005, p. 1125), Francis et al. (2005, p. 2), Aboody e Hughes e Liu (2005, p. 651). Por outro lado, no Brasil o foco predominante das pesquisas é na relação entre o nível de divulgação e o impacto no custo de capital próprio, assim como explorado em Alencar (2005, p. 7), Nakamura et al. (2006, p. 11) e Lima (2007, p. 7). Porém, poucas pesquisas procuraram averiguar a relação entre GR e custo de capital próprio ou de terceiros. Apesar disso, alguns trabalhos nacionais, 
como Martinez (2001), Rodrigues (2006), Decourt, Martinewski e Pietro Neto (2007) e Coelho e Lima (2007) encontraram evidências de que no Brasil as empresas gerenciam seus resultados de modo a interferir na análise dos agentes do mercado.

Diante do exposto, torna-se interessante verificar em pesquisas internacionais, se os usuários das informações contábeis, como os investidores e os credores, elevam seu retorno exigido quando percebem que há maiores chances de as empresas brasileiras gerenciarem seus resultados contábeis. Assim questiona-se: Qual a relação entre o custo de capital próprio e de terceiros das companhias brasileiras de capital aberto e os accruals discricionários, proxy para gerenciamento de resultados? Para responder a essa questão, o presente estudo examina a relação entre o gerenciamento de resultados contábeis das empresas brasileiras e seus custos de capital, a partir da seguinte hipótese: empresas com níveis de gerenciamento de resultados contábeis mais elevados possuem maiores custos de capital próprio e de capital de terceiros.

\section{REVISÃO BIBLIOGRÁFICA}

\subsection{Conflito de Agência}

Jensen e Meckling (1976, p. 4) desenvolveram uma linha de raciocínio sobre a relação entre acionistas e gestores das empresas, no denominado conflito de interesses entre as partes, ou conflito de agência. Esse conflito pode ser percebido entre um agente e um principal cujos interesses divergem, sendo que eles ocupam posições diferentes e que as atitudes de um podem impactar nos interesses do outro. Dessa forma, pode-se perceber que o conflito de agência ocorre quando uma pessoa não acumula a mesma função, seja de acionista e de gerente da empresa ou de acionistas controladores e acionistas não-controladores.

Além disso, os conflitos de agência dificilmente serão evitados, e isso pode ser explicado pelo axioma de Klein e de Jensen e Meckling, segundo Andrade e Rossetti (2004, p. 86-87). Esse axioma levanta duas razões, pelas quais, os conflitos não podem ser evitados:

a) inexistência de contrato completo - pois o ambiente dos negócios está sujeito às turbulências que podem comprometer os resultados e não existe contrato capaz de abranger todas as contingências e respostas às mudanças; e

b) inexistência de agente perfeito - o ser humano tem uma força de interesse próprio que o leva a tomar decisões de forma a colocá-lo em melhor posição em relação a terceiros. O fato é que a natureza humana é utilitarista e racional; logo, as pessoas procuram ações para alcançar suas próprias preferências e objetivos.

Diante da impossibilidade de contratos completos e perfeitos, e pelo fato de necessitar dos gestores mais do que para a execução de ações previsíveis, a empresa acaba ficando exposta ao juízo gerencial, ou seja, ações mais voltadas aos objetivos dos gestores do que dos próprios acionistas. Mas, além dos contratos, seus termos e cláusulas, e dos custos envolvidos, existe ainda uma característica humana que se refere à maximização da própria utilidade, ou seja, as pessoas procuram por ações cujos resultados permitam-nas alcançarem seus interesses, conforme esclarece Jensen e Meckling (1976, p. 5).

Isso quer dizer que os problemas de agência surgem quando o bem-estar de uma parte é dependente de ações de outras partes, as quais podem ter interesses conflitantes com a primeira, fazendo com que tomem decisões caracterizadas por moral hazard, ou risco moral (CARVALHO, 2002, p. 19). O risco moral é característica das tomadas de decisões de um agente em detrimento às vontades do principal. Mas, além do risco moral, embora intimamente ligado a ele, tem-se a questão da assimetria informacional, a qual é uma alavanca para o conflito de agência. Essa assimetria ocorre quando nem todas as informações são 
conhecidas por ambas as partes (agentes e principais), ou seja, o administrador acaba por ter mais informações sobre os negócios da empresa do que o principal ou acionista, o qual não conhece as preferências dos administradores nem pode observar todas suas ações.

A contabilidade, nesse contexto, tem um papel fundamental na redução da assimetria de informações entre as empresas e os usuários fazendo um elo entre as partes ao permitir que os usuários (investidor/credor) conheçam a realidade econômica e financeira da empresa e, consequentemente, tenham bases sólidas que lhe permitam tomar decisões de alocação de recursos com base nessas informações. Os relatórios contábeis, por sua vez, são uma maneira de o usuário acompanhar o desempenho da empresa, os quais, portanto, devem conter informações transparentes, confiáveis, oportunas e relevantes, para assim contribuir com o papel da contabilidade de reduzir a assimetria informacional entre a companhia e seus usuários.

Mas, com base nas normas contábeis, é possível que o administrador possa optar por escolhas de critérios contábeis ao longo do tempo, exercendo certa discricionariedade. Essa discrição pode ser capaz de impactar na qualidade das informações contábeis, a ponto de permitir ao usuário análises condizentes com a realidade da empresa, mas pode ser utilizada de modo a elevar a assimetria informacional para com os usuários externos e os conflitos de interesses, o que, por sua vez, não permite que a contabilidade cumpra seu objetivo de bem informar seus usuários.

\subsection{Informação Contábil e Custo de Capital}

Um assunto de grande destaque no mercado de capitais e no meio acadêmico é a transparência das informações. A informação transparente é aquela que permite ao seu usuário verificar a realidade da empresa. Em se tratando das informações das demonstrações contábeis, elas seriam transparentes ao permitirem aos usuários conhecerem a verdadeira realidade econômico-financeira da companhia e, sua essência, segundo Dias Filho (2000, p. 47), está na redução das incertezas e dos riscos.

De acordo com Alencar (2005, p. 2), quando fornece informação, a contabilidade exerce um papel importante na administração dos conflitos de interesses e na redução da assimetria informacional. Afirma ainda que um dos resultados esperados quando se tem menor assimetria informacional é a redução no custo de capital, o que está de acordo com as afirmativas de Easley e O'Hara (2001, p. 1573) sobre o fato de que uma informação contábil mais precisa reduz o risco do investidor. Desse modo, parece haver uma relação entre a qualidade da informação divulgada e o retorno exigido dos fornecedores de recursos. Nesse ponto também concordam Francis et al. (2002, p. 5) e Francis, Khurana, e Pereira (2005, p. 1126).

Schadewitz e Blevins (1998) mencionam que, quando os investidores são racionais, acabam percebendo os possíveis riscos das empresas. Assim, evitam assumir posições acionárias em companhias em que a quantidade e a qualidade de evidenciação de informação é consideravelmente baixa em relação às suas expectativas. Dentro desse raciocínio, Lanzana (2004) afirma que quando uma empresa se compromete em fornecer informações de alta qualidade para o mercado, tem como consequência uma redução do risco de o investidor perder capital, atraindo mais fundos para o mercado de capitais, reduzindo também o risco de liquidez. Por outro lado, como exposto por Francis et al. (2002, p. 5), o investidor não informado encara uma forma de risco de informação sistemático e requer maiores retornos (maior custo de capital) como compensação.

Sobre a relação entre a qualidade da informação e o risco, Aboody, Hughes e Liu (2005, p. 651) alegam que, teoricamente, a informação pode ser correlacionada com o custo 
de capital por causa do risco da informação assimétrica ou informação incompleta. Francis, Khurana e Pereira (2005, p. 1127) salientam que a assimetria informacional é uma imperfeição do mercado que cria uma cunha entre os fundos de custo interno e externo da empresa. Assim, as companhias não conseguem ter acesso a custos baixos de financiamento externo.

Portanto, tais evidências parecem suportar a existência de uma relação entre a qualidade da informação divulgada aos usuários e o custo de capital das companhias. Quando a empresa se compromete com a qualidade de suas informações, os usuários podem avaliar o risco e o retorno com mais segurança e, com isso, tomar suas decisões de investimento.

\subsection{Importância do Lucro e do Gerenciamento de Resultados}

A contabilidade tem como objetivo informar os seus usuários, de forma a permitir-lhes um acompanhamento e análise do desempenho econômico-financeiro das empresas e fornecer elementos ao processo de tomada de decisão. Por meio da identificação, mensuração e comunicação de informações econômicas, financeiras e sociais, a contabilidade subsidia seus usuários no processo de tomada de decisões. As informações geradas configuram-se como um dos principais meios de comunicação entre a empresa e os agentes econômicos. Ao apresentarem os fatos acontecidos ao longo da existência das entidades, permitem a avaliação da situação econômico-financeira atual e prospectiva da empresa. Assim, a contabilidade contempla os interesses dos acionistas em predizer os lucros, além de possibilitar a estimação do valor da empresa (COLAUTO; BEUREN, 2004, p. 4).

Segundo Formigoni, Paulo e Pereira (2007, p. 3), os relatórios contábeis são meios para a administração comunicar o desempenho econômico empresarial; o que os torna de extrema importância para assegurar a qualidade da informação contábil, a qual influencia a alocação de recursos, bem como a distribuição de riqueza entre os diversos agentes.

Referindo-se ao lucro como informação, tem-se que o objetivo primordial da sua divulgação, segundo Hendrinksen e Van Breda (1999, p. 174-205), é o fornecimento de informações úteis àqueles que estão mais interessados nos relatório financeiros, pois é uma medida da eficiência da gestão e é usado para predição da trajetória porvindoura da empresa e como medida de desempenho e orientação para decisões gerenciais futuras. Para esses autores, os investidores e credores normalmente recorrem ao lucro para avaliação da capacidade de geração de resultados, para predizer lucros futuros, para avaliar o risco de investir na empresa ou mesmo para emprestar dinheiro. Os autores afirmam que o lucro medido com base no regime de competência fornece medidas úteis de eficiência da empresa e informação relevante para a predição de sua atividade futura. De modo semelhante, Francis et al (2002, p. 5) também afirmam que maior qualidade nos resultados fornece um sinal mais preciso ao investidor, assim como Aboody, Hughes e Liu (2005, p. 11), que expõem que a qualidade do resultado pode ser vista como uma medida de assimetria informacional.

De acordo com Hendrinksen e Van Breda (1999, p. 177), a grande deficiência dos lucros publicados é a possibilidade de distorção devido à natureza arbitrária dos procedimentos contábeis, pois a manipulação dos resultados da empresa é capaz de influenciar o usuário da informação em suas decisões, modificando seu julgamento sobre a situação da entidade. Tal possibilidade de manipulação ocorre devido à discricionariedade das escolhas contábeis sobre algumas transações e eventos econômicos. Segundo Formigoni, Paulo e Pereira (2007, p. 2), essa subjetividade estará presente na mensuração e evidenciação das demonstrações contábeis, consequentemente, afetando os resultados da empresa. 
Frente à existência de várias normas e práticas contábeis, os gestores podem optar por métodos consistentes com a legislação e mesmo assim apresentarem informações da maneira que lhes interessar. O que é confirmado por Verrechia (1983, p. 179) ao salientar que o gestor exerce a discrição escolhendo o ponto ou o grau da qualidade da informação. A esse respeito, Lopes e Martins (2005, p. 55) destacam que os gestores selecionam as informações mais relevantes aos seus interesses, o que está relacionado com a administração de accruals, que são as diferenças entre o resultado reconhecido em determinado momento e o fluxo de caixa correspondente, ocorrido em momentos diferentes. Além disso, eles afirmam que "os administradores podem manipular as informações, fornecendo números com o objetivo de iludir os usuários a respeito da 'real' situação da empresa".

Portanto, quando o gestor age de forma oportunista, ele pode estar gerenciando os resultados da empresa. Healy e Wahlen $(1999$, p. 368) afirmam que o gerenciamento de resultados contábeis ocorre quando o administrador faz julgamento no processo de mensuração e evidenciação, alterando as informações contábeis reportadas e afetando a percepção do usuário sobre a verdadeira situação econômica da empresa. Existe outra abordagem que considera o GR como forma de ludibriar o usuário, como definido por Schipper (1989), Healey e Whalen (1999, p. 368) e Leuz, Nanda e Wysocki (2003, p. 506). Por outro lado, há definições que não implicam em qualificar o gerenciamento de resultados como uma atitude oportunista, como a de Field, Lys e Vincent (2001, p. 260): "gerenciamento de resultados é quando o gestor exerce seu poder discricionário sobre os números contábeis com ou sem restrição. Tal discrição pode ser maximizar o valor da firma ou ser oportunista".

No que se refere ao oportunismo, Christie e Zimmerman (1994, p. 541) afirmam que ele ocorre quando as decisões dos gestores aumentam sua riqueza, mas não cria um aumento líquido na agregação de riqueza da empresa, ou seja, quando o sistema de controle da companhia permite que o gestor enriqueça mais do que o esperado e se erros são feitos na redação inicial dos contratos. Essa situação caracteriza uma transferência de riqueza de acionistas e credores para os gestores. Portanto, as escolhas visando alcançar primordialmente o objetivo próprio podem ser encaradas como um comportamento oportunista.

Assim, a prática de gerenciamento de resultados por meio de atitudes oportunistas pode trazer prejuízos aos usuários da informação contábil, devido ao fato de que os demonstrativos podem não representar a verdadeira realidade econômico-financeira da companhia e sim interesses particulares de agentes. A respeito de usuários que podem ser prejudicados, Paulo, Corrar e Martins (2006, p. 1) destacam: a) os investidores, no que tange a tomada de decisões, b) os analistas financeiros que fazem previsões para seus clientes, c) as instituições de crédito e de financiamento que precisam analisar risco, entre outros.

Nesse cenário, pode-se questionar se as empresas que praticam gerenciamento de resultados e não divulgam as informações de forma transparente estão interferindo no julgamento dos investidores no que tange à tomada de decisões quanto à alocação de seus recursos. Em função disso, segundo a teoria abordada anteriormente, é possível esperar um aumento no custo de capital das companhias, já que os investidores acabam por cobrar um prêmio devido à possibilidade percebida de sofrer com a assimetria informacional.

Para tanto, considerar-se-á no presente estudo que o gestor, diante da discricionariedade que lhe cabe, pode tomar atitudes e escolher ações de modo a impactar no resultado a ser divulgado, o que é denominado de gerenciamento de resultados. Como dito, suas ações podem ser oportunistas ou não, mas ambas são capazes de influenciar o resultado. Portanto, o gerenciamento de resultados também pode ser um ato oportunista ou não. 


\subsection{Pesquisas Nacionais e Internacionais}

Pesquisas nacionais e internacionais estão focando as relações entre divulgação de informações, assimetria informacional, custo de capital e gerenciamento de resultados contábeis. No Brasil, um dos trabalhos pioneiros no contexto de gerenciamento de resultados foi o de Martinez (2001), o qual verificou se as empresas fazem GR e com que finalidade. Em seguida, Martinez (2004) analisou os modelos existentes para estimação de accruals discricionários, proxy empírica para gerenciamento de resultados. Com a análise de 147 empresas no período de 1996 a 1999, o autor chegou à conclusão de que o modelo de Kang e Sivaramakrishnan (1995, p. 358), ou modelo KS, é o mais acurado para o contexto brasileiro. Desde então, pesquisas no âmbito do gerenciamento de resultado foram desenvolvidas, relacionando o tema com: oferta pública de ações (PAULO, 2006), governança corporativa (RODRIGUES, 2006; RAMOS e MARTINEZ, 2006), diferimento de impostos (PAULO, CORRAR e MARTINS, 2006), debêntures (MARTINEZ e FARIA, 2007), alavancagem (COELHO e LOPES, 2007) etc. Percebe-se que a pesquisa envolvendo gerenciamento de resultados e custo de capital no mercado brasileiro é incipiente, apesar de algumas pesquisas internacionais já terem verificado essa relação.

Entre as pesquisas em mercados desenvolvidos, Sengupta (1998, p. 459), por exemplo, examinou se empresas com alto índice de qualidade de disclosure tem menor taxa de custo de dívida, encontrando essa relação. O tempo considerado foi de 1987 a 1991 e, a proxy de qualidade da informação foi obtida por meio da análise dos relatórios disponíveis no Report of the Financial Analysts Federation Corporate Information Committee (FAF).

Francis et al. $(2002$, p. 1) investigaram a relação entre qualidade dos resultados e custo da dívida e do capital próprio nos anos de 1988 a 1999. Para qualidade dos resultados, usaram os accruals calculados pelo modelo Jones Modificado de Dechow, Sloan e Sweeney (1995, p. 199), pelo modelo de Teoh et al. (1998, p. 1940) e pelo modelo de Dechow e Dichev (2002, p. 40). Eles encontraram que firmas com menor qualidade nos resultados têm maior custo de capital, evidenciado pelo baixo índice de classificação da dívida (ratings), e que as firmas com melhor qualidade dos resultados apresentam desconto de 80-160 pontos bases em seu custo da dívida e de 150-300 em seu custo de capital próprio. Concluíram que a menor qualidade dos resultados está associada com menor rating, maior custo da dívida e maior beta.

Francis et al. (2005, p. 295) averiguaram a relação entre qualidade dos accruals e o custo de terceiros e próprio. Trabalharam com dados disponíveis entre 1970 a 2001. Mediram a qualidade dos accruals como o desvio padrão dos resíduos da regressão, relacionando accruals correntes com fluxo de caixa (modelo de Dechow e Dichev, 2002, p. 40). Encontraram que uma qualidade mais pobre dos accruals (AQ) está associada com maiores custos de capital próprio e de terceiros - mais altos índices de despesa de juros por dívida e menor classificação de dívida (debt ratings) - do que firmas com melhores AQ.

Aboody, Hughes e Liu (2005, p. 651) analisaram se a qualidade nos resultados, medida por accruals anormais, é uma proxy de assimetria de informação que afeta o custo de capital, encontrando evidências consistentes com essa informação. Além disso, verificaram que se os insiders possuem maior lucratividade quando a qualidade dos resultados é baixa, é porque possuem mais informação privada. O custo de capital foi calculado pelo APT (Arbritage Princing Theory); para cálculo da qualidade dos resultados, usaram modelo de Dechow, Sloan e Sweeney (1995, p. 199), baseado no accrual anormal, e de Dechow Dichev (2002, p. 40); o período utilizado foi de janeiro de 1985 a novembro de 2003.

É possível perceber que o estudo sobre gerenciamento de resultados apresenta-se mais desenvolvido no meio acadêmico internacional, com diversas linhas de pesquisa, entre elas, o 
foco abordando GR e custo de capital das empresas. No Brasil, o tema é recente e há vários estudos sendo feitos em diferentes frentes. Entretanto, como as pesquisas nacionais não se aprofundaram na relação entre GR e custos de capital, assim como pesquisadores internacionais vêm fazendo, torna-se oportuno o desenvolvimento desta pesquisa no Brasil, com o intuito de verificar se as relações encontradas nas pesquisas internacionais se mantêm no mercado nacional com características institucionais, por vezes, distintas.

\section{METODOLOGIA}

\subsection{Dados}

A pesquisa foi aplicada às empresas brasileiras de capital aberto, no período de 2004 a 2006, sendo que todos os dados foram obtidos do Economática ${ }^{\circledR}$. Justifica-se o intervalo de tempo pelo fato de que a utilização dos modelos para cálculo dos accruals discricionários exige um número elevado de variáveis. Um intervalo de tempo mais extenso reduziria o número de empresas na amostra por causa daquelas que não constavam em períodos anteriores. Assim, para manter maior número de companhias na amostra foi necessário trabalhar com um intervalo de três anos.

A princípio, a amostra era composta de 407 empresas. Após eliminar as instituições financeiras, de seguros e fundos, a amostra final limitou-se a 142 empresas ou 426 empresasano.

\subsection{Medidas de Custo de Capital}

As variáveis representativas de custo de capital de terceiros e de custo de capital próprio empregadas nesse estudo foram as que constam no Quadro 1.

\begin{tabular}{|c|c|}
\hline \multicolumn{2}{|c|}{ Variáveis de Custos de Capital } \\
\hline Variável & Proxy para \\
Ki & Custo de capital de terceiros \\
Kd & Custo de capital de terceiros \\
Beta & Custo de capital próprio \\
\hline
\end{tabular}

Quadro 1 - Variáveis de custo de capital

Para o cálculo do Ki de cada empresa, foi aplicada a seguinte fórmula:

$$
K i_{j, t}=\frac{D F_{j, t}}{P O_{j, t}}(\text { Equação 1) }
$$

Onde:

$K i_{j, t}$ é o custo da dívida da empresa j no ano t;

$D F_{j, t}$ é a despesa financeira de curto e longo prazo da empresa j no ano t; e

$P O_{j, t}$ é o passivo oneroso da empresa j no ano t.

Para o cálculo dessa medida, o passivo oneroso foi obtido no final de cada ano. Diferentemente, a variável $\mathrm{Kd}$, calculada pelo Economática ${ }^{\circledR}$, considera esse dado no início do ano. Vale ressaltar que o passivo oneroso utilizado tanto no Ki como no Kd compreende: 


$$
P O=F C P+F L P+D C P+D L P(\text { Equação } 2)
$$

Em que:
$F C P$ é o financiamento de curto prazo;
$F L P$ é o financiamento de longo prazo;
$D C P$ são as debêntures de curto prazo;
$D L P$ são as debêntures de longo prazo.

Quanto ao custo de capital próprio, foi utilizado o beta obtido diretamente do Economática $^{\circledR}$. Seu cálculo é realizado a partir das oscilações da ação da empresa e do índice de mercado, sendo sua fórmula a seguinte (http://www.economatica.com ):

$$
\operatorname{Beta}=\frac{\operatorname{Cov}\left(R_{i}, R_{M}\right)}{\sigma^{2}\left(R_{M}\right)}(\text { Equação } 3)
$$

Onde:

$\operatorname{Cov}\left(R_{i}, R_{M}\right)$ : covariância entre o retorno da ação e o retorno de mercado; $\sigma^{2}\left(R_{M}\right)$ : variância do retorno de mercado.

\subsection{Medidas de Gerenciamento de Resultados}

Para relacionar custo de capital com gerenciamento de resultados, consideraram-se alguns modelos existentes para o cálculo dos accruals discricionários. Esses modelos consideram que a discricionariedade seja uma proxy para o gerenciamento de resultados.

Os modelos representativos dos accruals totais, segundo Paulo, Corrar e Martins (2006, p. 3), permitem que se alcancem os accruals discricionários pelos resíduos das regressões. Dentre eles tem-se Healy (1985, p. 96), Jones (1991, p. 211), Jones Modificado por Dechow, Sloan e Sweeney (1995, p. 199), Kang e Sivaramakrishnan (1995, p. 358).

Francis et al. (2002, p. 6) calcularam suas medidas de qualidade de resultados - que é o oposto de gerenciamento de resultados. Por exemplo, uma empresa com alto gerenciamento de resultados, necessariamente, possui baixa qualidade de resultados - usando o modelo de Dechow, Sloan e Sweeney (1995, p.199) (ou modelo Jones Modificado), o modelo seguindo Teoh, Welch e Wong (1998, p. 1940) e o modelo de Dechow e Dichev (2002, p. 40). Como esse último utiliza o fluxo de caixa das empresas para estimar a qualidade dos resultados, e como essa demonstração não era obrigatória no Brasil até a publicação da Lei n. 11.638/07, não foi possível aplicá-lo, pois poucas empresas disponibilizam tal demonstração. Portanto, esse modelo foi substituído pelo modelo de Kang e Sivaramakrishnan (1995, p. 358) (modelo $\mathrm{KS})$.

O modelo KS, segundo Martinez (2001, p. 95), é aquele que descreve mais eficientemente o processo da definição dos accruals em relação aos modelos hoje existentes. Além disso, foi utilizada nos trabalhos de Formigoni, Paulo e Pereira (2007, p. 8), Paulo, Corrar, Martins (2006, p. 8), Cardoso e Martinez (2006, p. 5), entre outros.

Em suma, neste trabalho, os modelos utilizados para cálculo do AD foram: Jones Modificado (JM), Teoh, Welch e Wong (T) e Kang e Sivaramakrishnan (KS). Esses modelos partem do raciocínio de que os accruals totais são compostos por itens discricionários e não discricionários, conforme ilustrado a seguir: 


$$
A T=A D+A N D(\text { Equação 4) }
$$

Em que:

$A T$ : accruals totais;

$A D$ : accruals discricionários; e

$A N D$ : accruals não discricionários.

Estudos nessa área indicam que o accrual total pode ser calculado por meio do balanço patrimonial ou mesmo pelo fluxo de caixa da empresa, assim como os accruals não discricionários. Mas os accruals discricionários não são tão fáceis de serem observados. Porém, se é possível observar os accruals totais e os não discricionários, o accrual discricionário pode ser encontrado por diferença. Esse é o raciocínio de tais modelos. Assim:

$$
A D=A T-A N D(\text { Equação 5) }
$$

O accrual total é calculado da seguinte maneira, segundo Healy (1985), Jones (1991, p. 207), Dechow, Sloan e Sweeney (1995, p. 203), Pae (2005, p. 8), Gu, Lee e Rosett (2005, p. 321):

$$
A T_{j, t}=\Delta A C_{j, t}-\Delta P C_{j, t}-\Delta \text { Dispon }_{j, t}+\Delta P f C P_{j, t}-D E P A_{j, t}(\text { Equação 6) }
$$

Em que:

$A T_{j, t}$ : o accrual total da empresa j no período t;

$\Delta A C_{j, t}$ : variação do ativo circulante da empresa $\mathrm{j}$ entre os anos t-1 e t;

$\Delta P C_{j, t}$ : variação do passivo circulante da empresa $\mathrm{j}$ entre os anos $\mathrm{t}-1 \mathrm{e} \mathrm{t}$;

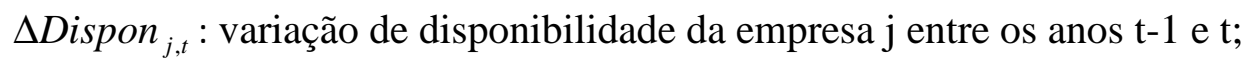

$\Delta P f C P_{j, t}$ : variação do passivo financeiro de curto prazo da empresa $\mathrm{j}$ entre os anos t-1 e t; e

$D E P A_{j, t}$ : despesa de depreciação e amortização da empresa j no período t.

O accrual total corrente é dado pela seguinte equação:

$$
A T C_{j, t}=\Delta A C_{j . t}-\Delta P C_{j, t}-\Delta \text { Dispon }_{j, t}+\Delta P f C P_{j, t}(\text { Equação 7) }
$$

Em que:

$A T C_{j, t}:$ accrual total corrente da empresa j no período t.

Os accruals discricionários, com cálculo baseado no modelo de Jones Modificado, foram encontrados seguindo a seguinte equação:

$$
\frac{A T_{j, t}}{\text { Asset }_{j, t-1}}=\kappa_{1} \frac{1}{\text { Asset }_{j, t-1}}+\kappa_{2} \frac{\Delta \operatorname{Rev} v_{j . t}}{\text { Asset }_{j, t-1}}+\kappa_{3} \frac{P P E_{j, t}}{\text { Asset }_{j, t-1}}+\varepsilon_{j, t}(\text { Equação 8) }
$$


Em que:

$A T_{j, t}:$ accrual total da empresa j no período t;

Asset $_{j, t-1}$ : ativo total da empresa j no início do período (t-1);

$\Delta \operatorname{Re} v_{j . t}$ : variação da receita líquida da empresa j entre os anos t-1 e t; e

$P P E_{j . t}$ : investimento, imobilizado, diferido e intangíveis brutos da empresa j no ano t.

Os accruals não discricionários, por sua vez, são calculados da seguinte maneira:

$$
A N D_{j, t}=\hat{\kappa}_{1} \frac{1}{\text { Asset }_{j, t-1}}+\hat{\kappa}_{2} \frac{\left(\Delta \operatorname{Rev}_{j . t}-\Delta C R_{j . t}\right)}{\text { Asset }_{j, t-1}}+\hat{\kappa}_{3} \frac{P P E_{j . t}}{\text { Asset }_{j, t-1}}+\mathcal{E}_{j, t}(\text { Equação 9) }
$$

Em que:

$A N D_{j . t}:$ Accrual não discricionário da empresa j no período t;

$\Delta C R_{j . t}$ : variação de Contas a Receber da empresa $\mathrm{j}$ entre $\mathrm{t}-1 \mathrm{e} \mathrm{t}$.

Por fim, os accruals discricionários provêm de:

$$
A D_{j, t}=\frac{A T_{j, t}}{A s s e t_{j, t-1}}-A N D_{j, t}(\text { Equação 10) }
$$

Em seguida, tem-se a forma de cálculo dos accruals discricionários por meio da metodologia de Teoh, Welch e Wong (1998, p. 1940):

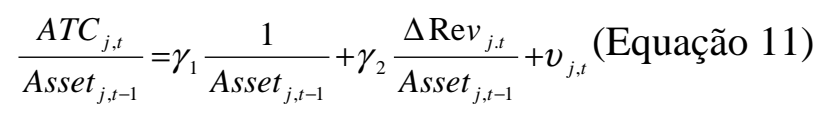

Por sua vez, o AND e o AD são calculados respectivamente por:

$$
\begin{gathered}
A N D_{j, t}=\hat{\gamma}_{1} \frac{1}{\text { Asset }_{j, t-1}}+\hat{\gamma}_{2} \frac{\left(\Delta \operatorname{Re} v_{j . t}-\Delta C R_{j . t}\right)}{A s s e t_{j, t-1}}(\text { Equação 12) } \\
A D_{j, t}=\frac{A T C_{j, t}}{\text { Asset }_{j, t-1}}-A N D_{j, t}\left(\text { Equação 13) }^{-13}\right.
\end{gathered}
$$

Quanto ao modelo KS, os accruals discricionários são obtidos pelos resíduos da seguinte regressão:

$$
A T_{j, t}=\phi_{0}+\phi_{1} \times\left[\frac{C R_{j, t-1}}{\operatorname{Rev} v_{j, t-1}} \times \operatorname{Rev} v_{j, t}\right]+\phi_{2} \times\left[\frac{A P B_{j, t-1}}{E X P_{j, t-1}} \times E X P_{j, t}\right]+\phi_{3} \times\left[\frac{D E P_{j, t-1}}{P P E_{j, t-1}} \times P P E_{j, t}\right]+v_{j, t}(\text { Equação 14) }
$$


$A P B_{j, t-1}$ : capital de giro líquido sem considerar contas a receber da empresa $\mathrm{j}$ no período t-1;

$E X P_{j, t-1}$ : despesa operacional antes da depreciação e amortização da empresa j no período t-1;

$E X P_{j, t}$ : despesa operacional antes da depreciação e amortização da empresa j no período t;

$D E P_{j, t-1}$ : despesa de depreciação e amortização da empresa j no período t-1;

Algumas considerações a respeito da obtenção desses dados utilizados nos modelos expostos anteriormente devem ser feitas em função das características do banco de dados utilizado. A variável "despesa de depreciação e amortização do período" não está segregada entre o que se refere ao imobilizado, aos investimentos, ao diferido ou aos intangíveis. Portanto, está englobando todas essas depreciações e amortizações. Em função disso, na variável PPE dos modelos JM e KS foi necessário considerar o saldo de ativo permanente bruto.

Vale ressaltar que as regressões dos modelos: JM, Teoh e KS, foram realizadas por setor. O objetivo era minimizar o impacto de fatores ambientais ou econômicos dos setores que poderiam afetar as empresas e estarem refletidos nos modelos, pois, teoricamente, as empresas do mesmo setor estão voltadas para características e impactos ambientais semelhantes. Contudo, para melhorar essa situação, outra solução seria calcular os accruals discricionários dos modelos por meio do método de dados dispostos em painel. Na Tabela 1 tem-se as estatísticas dos três modelos para alguns setores.

Tabela 1 - Estatística dos modelos JM, Teoh e KS para alguns setores

\begin{tabular}{|c|c|c|c|c|c|c|}
\hline \multirow[b]{2}{*}{ Modelos } & \multirow[b]{2}{*}{ Variáveis } & \multicolumn{5}{|c|}{ Setores } \\
\hline & & Comércio & Minerais & $\begin{array}{l}\text { Telecomuni } \\
\text {-cações }\end{array}$ & Construção & Têxtil \\
\hline \multirow{5}{*}{$\mathrm{JM}$} & $1 /$ Asset $_{j, t-1}$ & $\begin{array}{c}0,09 \\
2,67(* *)\end{array}$ & $\begin{array}{l}-0,38 \\
-0,53 \\
\end{array}$ & $\begin{array}{c}-0,08 \\
-2,04(* *) \\
\end{array}$ & $\begin{array}{l}0,04 \\
0,82 \\
\end{array}$ & $\begin{array}{l}0,05 \\
0,87\end{array}$ \\
\hline & $\Delta \operatorname{Re} v_{j . t} /$ Asset $_{j, t-1}$ & $\begin{array}{c}-0,21 \\
-2,56(* *) \\
\end{array}$ & $\begin{array}{c}2,13 \\
2,14(*) \\
\end{array}$ & $\begin{array}{c}-0,17 \\
-3,07(* * *) \\
\end{array}$ & $\begin{array}{l}0,63 \\
1,93 \\
\end{array}$ & $\begin{array}{c}0,40 \\
3,54(* * *) \\
\end{array}$ \\
\hline & $P P E_{j . t} /$ Asset $_{j, t-1}$ & $\begin{array}{c}-0,07 \\
-2,17(* *) \\
\end{array}$ & $\begin{array}{l}0,11 \\
0,19\end{array}$ & $\begin{array}{l}-0,04 \\
-1,47 \\
\end{array}$ & $\begin{array}{l}-0,40 \\
-1,16 \\
\end{array}$ & $\begin{array}{c}-0,14 \\
-2,46(* *) \\
\end{array}$ \\
\hline & $\mathrm{R}^{2}$ & $30 \%$ & $45 \%$ & $44 \%$ & $46 \%$ & $33 \%$ \\
\hline & $\mathrm{F}$ & $3,95(* *)$ & $4,34(* *)$ & $17,4(* * *)$ & $4,43(* *)$ & $8,98(* * *)$ \\
\hline \multirow{4}{*}{$\begin{array}{l}\text { Teoh, } \\
\text { Welch e } \\
\text { Wong }\end{array}$} & $1 /$ Asset $_{j, t-1}$ & $\begin{array}{c}0,06 \\
3,07(* * *) \\
\end{array}$ & $\begin{array}{c}-0,18 \\
-1,96(*) \\
\end{array}$ & $\begin{array}{c}-0,02 \\
-1,76(*) \\
\end{array}$ & $\begin{array}{c}0,002 \\
0,06 \\
\end{array}$ & $\begin{array}{c}-0,05 \\
-2,12(* *) \\
\end{array}$ \\
\hline & $\Delta \operatorname{Re} v_{j . t} /$ Asset $_{j, t-1}$ & $\begin{array}{l}-0,12 \\
-1,63 \\
\end{array}$ & $\begin{array}{c}2,00 \\
3,14(* *)\end{array}$ & $\begin{array}{l}-0,02 \\
-0,71\end{array}$ & $\begin{array}{c}0,80 \\
2,69(* *)\end{array}$ & $\begin{array}{c}0,40 \\
3,47(* * *)\end{array}$ \\
\hline & $\mathrm{R}^{2}$ & $11 \%$ & $53 \%$ & $1 \%$ & $44 \%$ & $26 \%$ \\
\hline & $\mathrm{F}$ & 2,65 & $9,86(* *)$ & 0,51 & 7,27 & $12,04(* * *)$ \\
\hline \multirow{6}{*}{ KS } & $\phi_{0}$ & $\begin{array}{c}0,18 \\
2,76(* *) \\
\end{array}$ & $\begin{array}{l}-0,38 \\
-0,39 \\
\end{array}$ & $\begin{array}{l}0,03 \\
1,32 \\
\end{array}$ & $\begin{array}{l}0,02 \\
0,64\end{array}$ & $\begin{array}{c}0,002 \\
0,04 \\
\end{array}$ \\
\hline & $\left(C R_{j, t-1} / \operatorname{Re} v_{j, t-1}\right) \times \operatorname{Re} v_{j, t}$ & $\begin{array}{l}-0,15 \\
-1,35\end{array}$ & $\begin{array}{l}0,02 \\
0,01\end{array}$ & $\begin{array}{l}0,01 \\
0,09\end{array}$ & $\begin{array}{c}0,59 \\
5,93(* * *)\end{array}$ & $\begin{array}{l}0,21 \\
1,45\end{array}$ \\
\hline & $\left(A P B_{j, t-1} / E X P_{j, t-1}\right) \times E X P$ & $\begin{array}{l}0,05 \\
0,48\end{array}$ & $\begin{array}{c}0,68 \\
3,66(* *)\end{array}$ & $\begin{array}{l}-0,03 \\
-1,38\end{array}$ & $\begin{array}{c}1,33 \\
7,07(* * *)\end{array}$ & $\begin{array}{c}0,39 \\
4,48(* * *)\end{array}$ \\
\hline & $\left(D E P_{j, t-1} / P P E_{j, t-1}\right) \times P P E$ & $\begin{array}{cc}3,96 \\
2,69(* *)\end{array}$ & $\begin{array}{l}-4,95 \\
-0,56\end{array}$ & $\begin{array}{c}1,34 \\
6,58(* * *)\end{array}$ & $\begin{array}{c}68,83 \\
6,3(* * *)\end{array}$ & $\begin{array}{c}2,80 \\
3,35(* * *)\end{array}$ \\
\hline & $\mathrm{R}^{2}$ & $32 \%$ & $58 \%$ & $71 \%$ & $89 \%$ & $50 \%$ \\
\hline & $\mathrm{F}$ & $3,24(*)$ & $4,69(*)$ & $34,52(* * *)$ & $22,92(* * *)$ & $11,71(* * *)$ \\
\hline
\end{tabular}


Com os dados obtidos, foi feita análise descritiva das variáveis, cálculo de correlação de Pearson e de Spearman e o teste não-paramétrico U de Mann-Whitney. A correlação, segundo Triola (1998, p. 235), existe entre duas variáveis quando uma delas está relacionada com a outra. A correlação de Spearman considera a correlação por postos e não exige suposição de normalidade dos dados, por ser um teste não-paramétrico. O teste U de MannWhitney, de acordo com Triola (1998, p. 326), testa a hipótese de que duas amostras independentes são provenientes de populações que têm a mesma distribuição. Esse teste é usado quando os dados são dispostos em uma sequência única e combinada, em que os valores altos e baixos devem se situar equitativamente entre as duas amostras. Se houver predominância de um em relação ao outro, há indícios de que as populações não sejam idênticas.

\section{RESULTADOS E ANÁLISE}

Primeiramente, foi feito um empilhamento das medidas de gerenciamento de resultados calculadas pelos modelos $\mathrm{JM}, \mathrm{T}$ e KS e das variáveis de custo da tabela 1 para as 426 empresas-ano.

A Tabela 2 mostra a evolução da média das medidas de GR, classificadas em ordem crescente. Por exemplo, 25\% das primeiras empresas possuem um GR apurado pelo JM em torno de 0,0089, 25\% das empresas seguintes têm um GR de 0,0288, enquanto que a observação mediana é de 0,0867 . Como a média da variável JM é de 0,3240 , percebe-se que há um conjunto de $25 \%$ de observações que possuem um alto gerenciamento de resultados (75-100\%), o que implica no valor da média. Análise semelhante pode ser feita para T e KS.

Tabela 2 - Informações descritivas das medidas de gerenciamento de resultados

\begin{tabular}{ccccccc}
\hline Métrica & Média & $\mathbf{0 - 2 5 \%}$ & $\mathbf{2 5 - 5 0 \%}$ & Mediana & $\mathbf{5 0 - 7 5 \%}$ & $\mathbf{7 5 - 1 0 0 \%}$ \\
\hline JM & 0,3240 & 0,0089 & 0,0288 & 0,0867 & 0,1004 & 0,3631 \\
T & 0,0700 & 0,0027 & 0,0106 & 0,0394 & 0,0437 & 0,1145 \\
KS & 0,1185 & 0,0033 & 0,0148 & 0,0454 & 0,0519 & 0,1308 \\
\hline
\end{tabular}

Além dessa análise, foi feita a correlação entre as variáveis de GR, como evidenciado na Tabela 3. Acima da diagonal encontram-se os coeficientes estimados pelo teste de correlação de Pearson e abaixo os de Spearman. A correlação maior ocorre, em ambos os testes, entre KS e JM, o que significa que esses dois modelos convergem no cálculo dos accruals discricionários. Porém, o modelo $\mathrm{T}$, apesar de significante, não apresentou correlação alta com medidas KS e JM.

Tabela 3 - Correlações gerenciamento de

\begin{tabular}{cccc}
\hline & $\mathrm{JM}$ & $\mathrm{T}$ & $\mathrm{KS}$ \\
\hline $\mathrm{JM}$ & & $0,131(*)$ & $0,979(*)$ \\
$\mathrm{T}$ & $0,304(*)$ & & $0,182(*)$ \\
$\mathrm{KS}$ & $0,459\left(^{*}\right)$ & $0,394(*)$ & \\
\hline
\end{tabular}

entre as medidas de resultados

(*) significante a1\%

A Tabela 4 representa um resumo da medida de gerenciamento JM e das variáveis de custo de forma a permitir uma análise de associação entre elas. Para fazer essa análise, a variável de gerenciamento de resultados pelo modelo JM foi classificada em ordem crescente 
e, após isso, dividida em quatro quartis. Consequentemente, essa tabela mostra a média das medidas de custo para cada quartil da distribuição ordenada pela medida JM.

Tabela 4 - Média das variáveis de custo por quartil de JM

\begin{tabular}{cccccc}
\hline Variáveis & Q1 & Q2 & Q3 & Q4 & Q4 - Q1 (Z) \\
\hline JM & 0,02 & 0,06 & 0,14 & 1,08 & \\
Beta & 0,68 & 0,60 & 0,46 & 0,56 & $-1,54$ \\
Ki $(\%)$ & 42,83 & 31,93 & 51,15 & 55,04 & $-0,91$ \\
Kd $(\%)$ & 49,82 & 50,91 & 64,76 & 69,85 & $-0,13$ \\
\hline
\end{tabular}

O grupo $1(\mathrm{Q} 1)$ da Tabela 4, que apresenta um baixo gerenciamento de resultados, tem um beta de 0,68 e o grupo 4 (Q4), que contém os mais altos índices de gerenciamento, de 0,56. Esses dados apontam uma relação contrária ao que era esperado, pois de acordo com essa tabela as empresas com baixo gerenciamento ou baixos accruals discricionários não usufruem de um custo de capital próprio menor em relação àquelas com alto gerenciamento. Esses resultados estão em discordância com aqueles encontrados por Francis et al. (2002, p. 22), que apresenta uma relação positiva entre beta e JM.

Diferentemente da análise anterior, as proxies de custo da capital de terceiros apresentam uma relação positiva com a medida JM. Pela Tabela 4, constata-se que à medida que o GR dado pelo modelo JM aumenta, as variáveis Ki e Kd também aumentam. Porém, o teste U de Mann-Whitney aplicado para as observações do primeiro quartil (Q1) e do último (Q4) não apresentou significância estatística. Portanto, não se pode afirmar que maior gerenciamento de resultados está acompanhado de aumento no custo de capital.

A Tabela 5 mostra a média das proxies de custo para cada quartil da distribuição classificada em ordem crescente da medida de GR dada pelo modelo T. A média do beta aumenta de Q1 para Q2 em concordância ao aumento do GR, porém o beta médio do último quartil indica um custo de capital menor se comparado ao primeiro quartil.

Tabela 5 - Média das variáveis de custo por quartil de T

\begin{tabular}{cccccc}
\hline Variáveis & $\mathrm{Q} 1$ & $\mathrm{Q} 2$ & $\mathrm{Q} 3$ & $\mathrm{Q} 4$ & $\mathrm{Q} 4-\mathrm{Q} 1(\mathrm{Z})$ \\
\hline $\mathrm{T}$ & 0,01 & 0,03 & 0,06 & 0,19 & \\
Beta & 0,58 & 0,68 & 0,47 & 0,56 & $-0,07$ \\
$\mathrm{Ki}(\%)$ & 29,93 & 31,65 & 62,28 & 57,21 & $-1,30$ \\
$\mathrm{Kd}(\%)$ & 44,86 & 38,01 & 56,56 & 96,08 & $-2,10(* *)$ \\
\hline
\end{tabular}

(**) significante a $5 \%$

As medidas de custo de capital de terceiros também acompanham o aumento de T. O quartil 1, com baixo gerenciamento de resultados, apresenta um Ki médio de 29,93\%, enquanto que o quartil 4 associado com alto gerenciamento apresenta um $\mathrm{Ki}$ médio de 57,21\%. Apesar disso, o teste de Mann-Whitney não mostrou diferença significativa entre esses quartis. Por outro lado, com a segunda variável representativa do custo de capital de terceiros, verifica-se, de modo geral, acompanhamento ao aumento do gerenciamento de resultados nos quartis, sendo que a diferença entre o primeiro e o quarto quartil foi estatisticamente significativa. Essa diferença pode representar o benefício para as empresas do quartil 1, em termos de custo, pelos baixos accruals discricionários apresentados.

A Tabela 6 mostra a mesma análise das duas tabelas anteriores, porém com a variável de gerenciamento de resultados calculada pelo modelo KS. Novamente a média do beta apresenta evidências contrárias ao que era esperado, porém a diferença entre os quartis extremos é menor em comparação às tabelas 4 e 5 e também não significativa. As medidas de 
custo da dívida aumentam conforme aumenta a medida KS, com exceção do Ki, de Q3 para Q4. O teste de Mann-Whitney indica que as observações entre os quartis 1 e 4 são significativamente diferentes.

Tabela 6 - Média das variáveis de custo por quartil de KS

\begin{tabular}{cccccc}
\hline Variáveis & $\mathrm{Q} 1$ & $\mathrm{Q} 2$ & $\mathrm{Q} 3$ & $\mathrm{Q} 4$ & $\mathrm{Q} 4-\mathrm{Q} 1(\mathrm{Z})$ \\
\hline KS & 0,01 & 0,03 & 0,07 & 0,36 & \\
Beta & 0,60 & 0,55 & 0,55 & 0,59 & $-0,54$ \\
Ki $(\%)$ & 19,45 & 44,51 & 62,71 & 54,39 & $-2,19\left(^{* *}\right)$ \\
Kd $(\%)$ & 31,34 & 55,33 & 65,34 & 83,45 & $-2,65\left(^{*}\right)$ \\
\hline
\end{tabular}

$(*)$ significante a $1 \%$ e $(* *)$ significante a $5 \%$

A análise das Tabelas 4, 5 e 6 pode não representar o verdadeiro efeito do gerenciamento de resultados nas variáveis de custo de capital. Nesse sentido, pesquisas futuras poderiam controlar outros fatores que afetam o custo de capital das empresas de capital aberto como: endividamento, tamanho, retorno dos ativos, cobertura dos juros (ou despesa financeira) e volatilidade dos resultados. Se eliminado o efeito destes outros fatores no custo de capital e se o mercado consegue distinguir a empresa com alto gerenciamento daquela com baixo gerenciamento de resultados, espera-se uma associação positiva entre as medidas de custo de capital e de GR, ou seja, um coeficiente positivo.

Além disso, cabe salientar que é razoável inferir que correlacionando gerenciamento de resultados com custo de capital em geral tenha como resultado a inexistência de qualquer relação. Afinal as motivações para gerenciar resultados são as mais diversas, como: a) influenciar a percepção do mercado de ações e elevar o preço das ações, segundo Verrechia (1983), Healy e Whalen (1999) e Field, Lys e Vincent (2001); b) motivos contratuais, para manter os covenants e outras restrições ou potencializar a obtenção de empréstimos, de acordo com Holthausen e Leftwhich (1983), Watts e Zimmerman (1990), Healy e Whalen (1999), Field, Lys e Vincent (2001) e Lopes e Martins (2005); c) preservar o cargo, busca de status e por perfeição e excelência profissional, como salientam Sunder (1997), Martinez (2001) e Andrade e Rossetti (2004). Dessa forma, pesquisas futuras poderiam fazer uma análise multivariada, considerando alguns destes aspectos, para melhorar o poder de explicação de testes estatísticos ou dos modelos econométricos, quando utilizados.

\section{CONSIDERAÇÕES FINAIS}

As empresas possuem relações estabelecidas por contratos, os quais não podem ser considerados completos ou perfeitos. Dada a dificuldade em se estabelecer as regras de uma relação contratual de forma que não se tenha assimetria de informação, comportamentos imperfeitos e divergência de interesses entre acionistas e administradores, cria-se a possibilidade de comportamento discricionário destes últimos.

Uma maneira de o gestor exercer seu comportamento discricionário é nas escolhas contábeis. Essa discricionariedade pode, por vezes, ser com a finalidade de alcançar objetivos próprios, ou seja, maximizar os próprios interesses, o que pode ser denominado de risco moral. Porém, quando o administrador, oportunistamente, interfere no conteúdo e na maneira de divulgar uma informação, ele acaba por impactar no resultado da empresa. Assim, a qualidade de transparência dessa informação pode ficar reduzida. De tal maneira, prevalece a assimetria de informações, o que pode interferir no custo de oportunidade dos agentes fornecedores de recursos. 
Em função disso, com a intenção de contribuir para os estudos nessa área, o presente trabalho procurou verificar a relação entre o gerenciamento de resultados contábeis das empresas brasileiras e o retorno exigido pelas fontes de financiamento. Os resultados encontrados apontaram para uma associação positiva entre as medidas de GR e o custo da dívida ( $\mathrm{Ki}$ e $\mathrm{Kd}$ ), ou seja, maior gerenciamento de resultados é acompanhado por maiores custos de capital de terceiros, resultado esse coerente com o encontrado por Francis et al. (2002, p. 17). O mesmo não foi observado para a proxy de custo de capital próprio.

Acredita-se que um estudo mais profundo do comportamento das variáveis possibilitaria encontrar resultados próximos ao de Francis et al. (2002, p. 17-26). Além disso, muitas críticas ainda existem sobre a capacidade dos modelos de gerenciamento de resultados na mensuração dos accruals discricionários. Vale ressaltar que esses modelos foram desenvolvidos em países com características econômicas e financeiras distintas daquelas encontradas no Brasil, o que pode estar interferindo nos resultados.

Destaca-se que há diferenças nas características do mercado acionário norte-americano com o mercado brasileiro. Uma delas é a pulverização do controle acionário, que influencia a relação de agência entre administradores, acionistas e credores. No Brasil, há uma concentração acionária na qual o acionista majoritário pode exercer maior monitoramento nas ações dos gestores, ou ainda, acumular as funções desse. Portanto, o gerenciamento de resultados contábeis pode ocorrer visando atingir objetivos dos acionistas controladores, os quais exercem grande influência sobre os gestores responsáveis pela publicação das demonstrações financeiras.

Por outro lado, os credores não podem monitorar todas as decisões contábeis da empresa, o que acentua a assimetria informacional. Em função disso, eles acabam sendo mais sensíveis às mudanças nas práticas contábeis ou às práticas pouco transparentes, encarando o gerenciamento de resultados como um ato oportunista, capaz de interferir na qualidade da informação publicada, o que eleva seu retorno exigido. Esse cenário do mercado nacional pode explicar os resultados obtidos nessa pesquisa em relação aos resultados das pesquisas internacionais.

Sugere-se também em pesquisas futuras o uso do modelo de Paulo (2007), desenvolvido posteriormente ao trabalho realizado neste artigo. $\mathrm{O}$ modelo foi elaborado no Brasil, buscando corrigir inconsistências teóricas e econométricas dos modelos desenvolvidos internacionalmente, assim seu uso poderia proporcionar maior robustez às conclusões.

\section{REFERÊNCIAS}

ABOODY, David; HUGHES, John; LIU, Jing. Earnings quality, insider trading, and cost of capital. Working Paper Series. Journal of Accounting Research, v. 43, n. 5, p. 651-673, 2005.

ALENCAR, Roberta C. Custo do capital próprio e nível de disclosure nas empresas brasileiras. Brazilian Business Review, v. 2, n. 1, jan./jun. p. 01-12, 2005.

ANDRADE, Adriana; ROSSETTI, José P. Governança corporativa: fundamentos, desenvolvimento e tendências. São Paulo: Atlas, 2004.

CARDOSO, Ricardo L.; MARTINEZ, Antonio L. Gerenciamento de resultados contábeis no Brasil mediante decisões operacionais. In: EnANPAD, 30, 2006, Salvador. Anais..., Rio de Janeiro: ANPAD, 2006. CD-ROM.

CARVALHO, Antonio G. Governança corporativa no Brasil e perspectiva. Revista de Administração, São Paulo, v. 37, n. 3, p. 19-32, jul./set. 2002. 
CHRISTIE, Andrew. A.; ZIMMERMAN, Jerold L. Efficient and opportunistic choices of accounting procedures: corporate control contest. The Accounting Review. v. 69, n. 4, oct., p. 539-566. 1994.

COELHO, Antônio. C.; LIMA, Iran. S. Gerenciamento de resultados contábeis no Brasil: comparação entre companhias de capital fechado e de capital aberto. In: EnANPAD, 31, 2007, Rio de Janeiro-RJ. Anais.... Rio de Janeiro: ANPAD, 2007. CD-ROM.

COELHO, Antonio C. D.; LOPES, Alexsandro B. Avaliação da prática de gerenciamento de resultados na apuração de lucro por companhias abertas brasileiras conforme seu grau de alavancagem financeira. Revista de Administração Contemporânea, v. 11, n. especial 2, p.121-144, 2007.

COLAUTO, Romualdo D.; BEUREN, Ilse M. A identificação de accruals no sistema de lucro contábil: o caso Parmalat Brasil. In: EnANPAD, 28, 2004, Curitiba-PR. Anais... Rio de Janeiro: ANPAD, 2004. CD-ROM.

COLLIS, Jill; HUSSEY, Roger. Pesquisa em administração: um guia prático para alunos de graduação e pós-graduação. Tradução Lucia Simioni. 2 ed., Porto Alegre: Bookman, 2005.

DECHOW, Patrícia M.; DICHEV, Ilia D. The quality of accruals and earnings: The role of accrual estimation errors. The Accounting Review. v. 77, p. 35-59, 2002.

DECHOW, Patrícia; SLOAN, R.; SWEENEY, A. Detecting earnings management. The Accounting Review. v. 70, n. 2, p.193-225, 1995. doi:10.2308/accr.2002.77.s-1.35

DECOURT, Roberta F.; MARTINEWSKI, André. L.; PIETRO NETO, José. Existe gerenciamento de resultados nas empresas com ações negociadas na Bovespa? In: CONGRESSO USP DE CONTROLADORIA E CONTABILIDADE, 7, 2007, São Paulo. Anais... São Paulo: FEA/USP, 2007. CD-ROM.

EILIFSEN, Aasmud; KNIVSFLA, Kjel H.; SAETTEM, Frod. Earnings manipulation: cost of capital versus tax. European Accouting Review. v. 8, n. 3, p. 481-491, Sep. 1999. doi:10.1080/096381899335899

EASLEY, David; O'HARA Maureen. Information and the cost of capital. Cornell University Working Paper. 2001. Disponível em: <http://papers.ssrn.com/sol3/papers.cfm?abstract_id=300715>. Acesso em: 20 nov. 2007.

FIELDS, Thomas D.; LYS, Thomas Z.; VINCENT, Linda. Empirical research on accounting choice. Journal of Accounting and Economics. v. 31, p. 255-307, 2001.

FORMIGONI, Henrique; PAULO, Edilson; PEREIRA, Carlos A. Estudo sobre o gerenciamento de resultados contábeis pelas companhias abertas e fechadas brasileiras. In: CONGRESSO ANPCONT, 1, 2007, Gramado. Anais... São Paulo: ANPCONT, 2007. CDROM.

FRANCIS, Jere R.; KHURANA, Inder K.; PEREIRA, Raynolde. Disclosure incentives and effects on cost of capital around the world. The Accounting Review. v. 80, n. 4, p. 11251162, oct. 2005. doi:10.2308/accr.2005.80.4.1125

FRANCIS, Jennifer; LAFOND, Ryan; OLSSON, Per; SCHIPPER, Katherine. The market pricing of earnings quality. Draft. Oct. 2002. Disponível em: 
<http://www.ebr360.org/downloads/mkt_pricing_earnings_qual.pdf >. Acesso em: 01 out. 2007.

FRANCIS, Jennifer; LAFOND, Ryan; OLSSON, Per M.; SCHIPPER, Katherine. The market pricing of accrual quality. Journal of Accounting and Economics. v. 39, p. 295-327, mar. 2005 .

GU, Zhaoyang; LEE, Chi-Wen J.; ROSETT, Joshua G. What determines the variability of accounting accruals? Review of Quantitative Finance and Accounting, v. 24, p. 313-334. 2005 .

HEALY, Paul M. The effect of bonus schemes of accounting decisions. Journal of Accounting and Economics, v.7, p. 85-107, Apr. 1985. doi:10.1016/0165-4101(85)90029-1

HEALY, Paul M.; WAHLEN, James M. A review of the earnings management literature and its implications for standard setting. Accounting Horizons, v. 13, 1999. p. 365-383. doi:10.2308/acch.1999.13.4.365

HENDRINKSEN, Eldon S.; VAN BREDA, Michael F. Teoria da Contabilidade. Tradução: Antonio Zoratto Sanvicente. São Paulo: Atlas, 1999.

HOLTHAUSEN, Robert W.; LEFTWICH, Richard W. The economic consequences of accounting choice: implications of costly contracting and monitoring. Journal of Accounting and Economics, North-Holland, v. 5, p. 77-117, Jun. 1983.

JENSEN, Michael C.; MECKLING, William. H. Theory of the firm: managerial behavior, agency costs and ownership structure. Journal of Financial Economics, Amsterdã, v. 3, n. 4, p. 305-360, Oct. 1976.

JENSEN, Michael C.; SMITH, Clifford W. Stockholder, manager, and creditor interests: applications of agency theory. Accepted Paper Series. [S.I]: Social Science Research Network, $1985 . \quad$ Disponível em: <http://papers.ssrn.com/sol3/papers.cfm?abstract_id=173461>. Acesso em: 01 out. 2006.

JONES, Jennifer. Earnings management during import relief investigations. Journal of Accounting Research. v. 29, p. 193-228, 1991. doi:10.2307/2491047

KANG, Sok-Hyon; SIVARAMAKRISHNAN, K. Issues in testing earnings management and an instrumental variable approach. Journal of Accounting Research. Oxford. v. 33, n. 2, p. 353-367, Autumn 1995.

LANZANA, Ana. P. Relação entre disclosure e governança corporativa das empresas brasileiras. São Paulo, 2004. Dissertação (Mestrado em Administração) - Faculdade de Economia, Administração e Contabilidade, Universidade de São Paulo.

LIMA, Gerlando. Influência do disclosure voluntário no custo de capital de terceiros. In: CONGRESSO USP DE CONTROLADORIA E CONTABILIDADE, 7, 2007, São Paulo. Anais... São Paulo: USP, 2007. CD-ROM.

LOPES, Alexsandro B.; MARTINS, Eliseu. Teoria da Contabilidade: uma nova abordagem. São Paulo: Atlas, 2005.

MARTINEZ, Antônio L. Gerenciamento dos resultados contábeis: estudo empírico das companhias abertas brasileiras. 2001. 153 f. Tese (Doutorado em Ciências Contábeis) Faculdade de Economia, Administração e Contabilidade, Universidade de São Paulo, São Paulo, 2001. 
MARTINEZ, Antonio L. Detectando earnings management no Brasil: estimando as acumulações discricionárias. In: CONGRESSO USP DE CONTROLADORIA E CONTABILIDADE, 4, 2004, São Paulo. Anais... São Paulo: USP, 2004. CD-ROM.

MARTINEZ, Anônio L.; FARIA, Mariana P. Emissão de debêntures e earnings management no Brasil. In: EnANPAD, 31, 2007, Rio de Janeiro-RJ. Anais... Rio de Janeiro: ANPAD, 2007. CD-ROM.

NAKAMURA, Wilson T.; GOMES, Elizabeth A.; ANTUNES, Maria T. P.; MARÇAL, Emerson F. Estudo sobre os níveis de disclosure adotados pelas empresas brasileiras e seu impacto no custo de capital. In: EnANPAD, 30, 2006, Salvador. Anais... Rio de Janeiro, 2006. CD-ROM.

PAE, Jinhan. Expected accrual models: the impact of operating cash flows and reversal of accruals. Review of Quantitative Finance and Accounting. v. 24, p. 5-22, 2005. doi:10.1007/s11156-005-5324-7

PAULO, Edilson. Gerenciamento de resultados e a oferta pública de ações pelas companhias abertas brasileiras. In: EnANPAD, 30, 2006, Salvador. Anais... Rio de Janeiro, 2006. CDROM.

PAULO, Edilson. Manipulação das informações contábeis: uma análise teórica e empírica sobre os modelos operacionais de detecção de gerenciamento de resultados. 2007. 269f. Tese (Doutorado em Contabilidade) - Faculdade de Economia, Administração e Contabilidade, Universidade de São Paulo, São Paulo, 2007.

PAULO, Edilson; CORRAR, Luiz J. MARTINS, Eliseu. Detectando gerenciamento de resultados pela análise do diferimento tributário. In: EnANPAD, 30, 2006, Salvador. Anais... Bahia, 2006. CD-ROM.

RAMOS, Gisele. M.; MARTINEZ, Antônio. L. Governança corporativa. Revista Contemporânea de Contabilidade. v. 1, n. 6, p. 143-164, jul./dez. 2006.

RODRIGUES, Adriano. Gerenciamento dos resultados contábeis através de receitas e despesas não-operacionais: estudo empírico das companhias "Nível 1"- Bovespa. In: CONGRESSO USP DE CONTROLADORIA E CONTABILIDADE, 6, 2006, São Paulo. Anais... São Paulo: USP, 2006. CD-ROM.

SCHADEWITZ, H. J.; BLEVINS, D. R. Major determinants of interim disclosures in a emerging market. American Business Review, n. 16, p. 41-55, Jan., 1998.

SCHIPPER, K. Commentary: Earnings management. Accounting Horizons. p.91-102, Dec. 1989.

SUNDER, Shyam. Theory of accounting and control. Ohio: South-Western Publishing, 1997.

TEOH, Siew H.; WELCH, Ivo; WONG, T. J. Wong. Earnings management and the long run underperformance of seasoned public offerings. Journal of Financial Economics. v. 50, p. 63-99. 1998.

TRIOLA, Mario F. Introdução à estatística. Tradução Alfredo Alves de Farias. 7 ed. Rio de Janeiro: LTC, 1998. 
VERRECCHIA, Robert E. Discretionary disclosure. Journal of Accounting and Economics. v. 5, p. 179-194, 1983. doi:10.1016/0165-4101(83)90011-3

WATTS, Ross L.; ZIMMERMAN, Jerold L. Positive accounting theory: a ten year perspective. The Accounting Review. v. 65, n. 1, p. 131-156, Jan. 1990. 